\title{
Evaluation of Gluten-Free Amaranth and Navy Bean Flour Blends on Quality of Sugar Cookies
}

\author{
Sean X. Liu ${ }^{1}$, Diejun Chen ${ }^{1} \&$ Jingyuan $\mathrm{Xu}^{2}$ \\ ${ }^{1}$ Functional Food Research Unit, National Center for Agricultural Utilization Research, USDA-ARS, USA \\ ${ }^{2}$ Plant Polymer Research Unit, National Center for Agricultural Utilization Research, USDA-ARS, USA \\ Correspondence: Sean X. Liu, Functional Food Research Unit, National Center for Agricultural Utilization \\ Research, USDA-ARS. 1815 N University Street, Peoria, IL 61604, USA. Tel: 1-309-681-6551. E-mail: \\ Sean.liu@ars.usda.gov
}

Received: September 27, 2017 Accepted: October 13, 2017 Online Published: November 7, 2017

doi:10.5539/jfr.v6n6p63

URL: https://doi.org/10.5539/jfr.v6n6p63

\begin{abstract}
Gluten-free sugar cookies were made from amaranth (Amaranthus caudatus) and navy bean flours of different ratios. The physical properties of flour blends, dough, and cookies were evaluated. This study found that navy bean and its blends with amaranth had greater water holding capacity (WHC) than that of wheat flour. The increased WHC was observed as the amount of navy bean flours increased in blends. The amaranth flour had the highest water soluble index (WSI) and pasting viscosities. The WSI, pasting viscosities and rheological elastic properties of composites were improved by amaranth flour. Differences were also found in geometrical and textural properties of the doughs and cookies. The cookies made from flour blends have lower width and spread factors; however, they had higher thickness and volume resulting in higher yield compared to wheat flour. Overall, the cookies made by amaranth, navy bean, and their blends were rated "acceptable" in color, flavor, texture, and overall acceptability in the sensory study. The flavorings of vanilla, cinnamon, and almond extracts improved sensory scores of cookies made from blends, making them indistinguishable from cookies using wheat flour. This study suggested that the amaranth-navy bean blends could be good gluten-free candidates for health-promoting food products.
\end{abstract}

Keywords: Amaranth grain, healthful foods, navy bean, water holding capacity, water soluble index, sensory study.

\section{Introduction}

As a crop, Amaranth (Amaranthus caudatus) has been consumed by people from different cultures for about 8,000 years. Amaranth grains comprise of thiamine, niacin, riboflavin, folate, and, in particular, vitamin E. The vitamin $\mathrm{E}$ amount in amaranth grains is similar to that in olive oil (USDA Nutrient Database, 2017). The amino acid lysine in amaranth flour is much richer than other grains (Myers \& Putnam, 1998). Amaranth also has similar dietary minerals of calcium, iron, magnesium, phosphorus, zinc, copper, and manganese to other grains such as wheat and oats (USDA Nutrient Database, 2017). Amaranth contains no gluten, but has about thirty percent more proteins than cereals of rice, sorghum and rye (Macvean \& Pöll, 1997; USDA Nutrient Database, 2017). Thus, amaranth has rich nutrient contents with gluten-free quality compared to other grains (Gallagher et al., 2004). In addition, amaranth seed oil could have health benefits for the people who have hypertension and cardiovascular disease. There are reports indicated that regularly consuming amaranth would reduce blood pressure and cholesterol levels and would improve antioxidant status and some immune parameters (Czerwiński et al., 2004; Martirosyan et al., 2007) via the plant stanols and squalene (Alegbejo, 2013). The interests in ancient grain amaranth have been revived since the 1970s due to its nutrition and gluten-free palatability.

Navy beans belong to pulses, which contain the excellent sources of minerals such as calcium, iron, phosphorus, potassium, zinc; dietary fiber (about 15.3\%); and proteins (approximately 22.3\%) (USDA National Nutrient Database, 2017). In addition, navy beans are well known for the rich vitamins and low glycemic indexes. Ha et al reported that navy beans in the diet could significantly reduce the cholesterol levels due to the abundant dietary fibers (Ha et al., 2014). It is the well accepted fact that dietary fiber can be the protection for obesity, heart disease, colon cancer, diabetes, and diverticulitis (McPherson, 1992). A new report implied that the bioactive compounds in pulses might lower the risk of diabetes, certain cancers, and heart disease (CGIAR, 
2016).

Ayo reported that the amaranth flour was characterized as a partial replacement for wheat flour in food formulations (Ayo, 2001). The wheat flour mixed with different amount of amaranth flours; and then the blends were fermented, molded, pan-proved and baked. The report showed that the loaf volume became lower with the amount of amaranth flour increased. When using $15 \%$ amaranth flour in the blend, the sensory qualities revealed the significant difference compared with wheat flour alone (Ayo, 2001). Most of the navy beans consumption in the United States is in the form of cooked whole beans. Currently, health concerned consumers demand plant gluten-free and protein enriched baking products. Gluten-free raw and popped amaranth flours breads and cookies were developed (de la Barca et al., 2010). Whole navy beans are used in many soup recipes and recently, navy bean pastes are used as vegetable dips. However, there have not been any published reports in the literature that have studied the properties of food products that were made from navy bean and amaranth.

Bakery products are a substantial segment of food products that have recently experienced a transformation from traditional staples towards more healthful, allergen free, and nutrition-fortified food products. Cookies containing navy bean flour may provide additional nutritional benefits for people with diabetic conditions particularly from low income families. Although navy bean has excellent nutritional value, its viscosity and cohesion are relatively low, rendering itself difficult to handle and process in many food productions. Amaranth, on the other hand, is high in nutritional components and viscosity (Inglett et al., 2014). The essential amino acids in amaranth and navy bean complement to each other (USDA Nutrient Database, 2017). Thus, this research was initiated to use gluten free amaranth and navy bean flour, and their composites (3:1, 1:1, and 1:3) in sugar cookies compared with wheat flour. This work studied the water holding, water solubility, pasting and rheological properties of amaranth, navy bean flour, and their composites with different ratios; explored the application feasibility of sugar cookies using gluten free amaranth flour and navy bean composites by evaluating the physical, geometrical and textural properties; and determined whether the amaranth-navy bean cookies are acceptable the color, texture, and flavor with a sensory evaluation. This work is important for promising a plant based nutritious gluten free diet since two million Americans are at risk for long-term health complications from gluten.

\section{Materials and Methods}

\subsection{Ingredients}

Organic amaranth flour (gluten-free) was purchased from Dakota Prairie Organic Flour Co. Harvey, ND, USA. Whole navy bean flour was obtained from Mrs. Glee's Foods Company, Hillman, MI, USA.

Cookie ingredients were: almond extract (Spice Islands Trading Co., San Francisco, USA), ammonium bicarbonate (My spice Sage company, Yonkers, NY, USA), brown sugar (C\&H sugar company, Crockett, CA, USA), cinnamon (Spice Islands Trading Co., San Francisco, USA), cocoa power (the Hershey Company, Hershey, PA,USA), nonfat dry milk (Carnation, Nestlé, Vevey Switzerland), shortening (Crisco, the J.M. Smucker company, Orrville, OH, USA), sodium bicarbonate ( Arm \& Hammer, Church and Dwight, Co., Inc., Princeton, NJ, USA), sugar (C\&H sugar company, Crockett, CA, USA), and Vanilla extract (McCormick \& Co., Inc., Hunt Valley, MD, USA).

\subsection{Flour Formulation}

The formulations of cookie flour are: amaranth flour; amaranth-navy bean composites 3:1, 1:1, and 1:3 respectively; and wheat flour. Amaranth flour was mixed with navy bean flour using a mixer (KitchenAid, St Joseph, MI, USA) for $2 \mathrm{~min}$. Then the mixtures were passed through a 20-mesh sieve followed by additional mixing in the mixer for $1 \mathrm{~min}$.

\subsection{Cookie Preparation}

Cookies were prepared according to the AACC method 10-52 for sugar cookie (AACC International, 2000) with some modifications (Inglett et al., 2016). The $22.5 \mathrm{~g}$ brown sugar, $2.3 \mathrm{~g}$ nonfat dry milk, $2.8 \mathrm{~g}$ salt, $2.3 \mathrm{~g}$ sodium bicarbonate, and $72 \mathrm{~g}$ sugar were mixed in a bowl using a whisk. Then, $100 \mathrm{~g}$ shortening was added into the mixture was and blended with a paddle beater in a mixing bowl using a KitchenAid mixer (St Joseph, MI, USA) at speed 2 for $3 \mathrm{~min}$, scraping down every minute. The solution of $1.1 \mathrm{~g}$ ammonium bicarbonate in $49.5 \mathrm{~g}$ water was then added and mixed for another 1 min at speed 2. After scraping down, they were mixed again for 1 minute at speed 2. The $225 \mathrm{~g}$ wheat flour, or $225 \mathrm{~g}$ amaranth flour, or $225 \mathrm{~g}$ amaranth-navy bean composites were added while mixing at speed 1 , and continued mixing for 2 min at speed 2 with scraping every $30 \mathrm{~s}$. The cookie dough was placed on a board and flattened by a rolling pin, and then cut by a cookie cutter. Cookies were baked at $205^{\circ} \mathrm{C}$ in a convention oven (XAF-113 LineChef Stefania, Cadco, Ltd. Winsted, CT, USA) for 
$10 \mathrm{~min}$, and cooled. The cookies were stored in a sealed plastic bag before measurements.

For flavored cookies, $1 / 4$ cup cocoa power (with additional water), or 2 teaspoons vanilla extract, or 2 teaspoons almond extract, or one and a half teaspoons cinnamon powder were mixed in cookie doughs respectively.

\subsection{Water Holding Capacity and Solubility Index}

The water holding capacity (WHC) of amaranth-navy bean blends was determined using a previous procedure with minor modifications (Ade-Omowaye, et al., 2003). Water capacity was calculated by the difference between the added water weight and decanted water weight on dry basis ( $\mathrm{g}$ of water absorbed $/ 100 \mathrm{~g}$ of dry sample).

Water solubility index (WSI) was determined by the method of Kaur and Singh (2006). WSI were calculated as follows:

WSI $=($ Weight of dissolved solids in supernatant/weight of dry solids $) \times 100$

\subsection{Pasting Property Measurement}

The pasting properties of amaranth-navy bean mixtures were measured using a Rapid Visco Analyzer (RVA-4, Perten Scientific, Springfield, IL, USA). Each sample ( $2.24 \mathrm{~g}$ d.b.) was comprised of a total weight of $28 \mathrm{~g}$ of suspension with deionized water in a RVA canister $\left(80 \mathrm{~g} \mathrm{~kg}^{-1}\right.$ solids, w/w). The viscosities of the suspensions were measured during the following heating and cooling procedures: suspensions were first equilibrated at $50^{\circ} \mathrm{C}$ for $1 \mathrm{~min}$, then heated to $95^{\circ} \mathrm{C}$ at a rate of $6.0^{\circ} \mathrm{C} / \mathrm{min}$, maintained at $95^{\circ} \mathrm{C}$ for $5 \mathrm{~min}$, and cooled to $50^{\circ} \mathrm{C}$ at rate of $6.0^{\circ} \mathrm{C} / \mathrm{min}$, and held at $50^{\circ} \mathrm{C}$ for $2 \mathrm{~min}$. A constant paddle rotating speed of $160 \mathrm{rpm}$ was maintained throughout the entire analysis except for $920 \mathrm{rpm}$ at the first $10 \mathrm{~s}$ to disperse the sample.

\subsection{Rheological Measurements of the Formulated Suspensions}

Samples from the RVA experiments were allowed to cool down to $25^{\circ} \mathrm{C}$, equilibrated overnight, and loaded on a stress-controlled rheometer (AR 2000, TA Instruments, New Castle, DE, USA) using a $6 \mathrm{~cm}$ diameter parallel acrylic plate geometry with $1 \mathrm{~mm}$ gap to the surface. The chamber was kept at $25^{\circ} \mathrm{C} \pm 0.1^{\circ} \mathrm{C}$ by a water circulation system. In order to keep the chamber moisture, the edge of the plate was sealed with mineral oil (Sigma Chemical Co., St Louis, MO, USA). A strain sweep experiment was initially conducted to determine the linear range of the viscoelasticity. Then a frequency sweep test was carried out with the linear strain $(0.5 \%)$ at frequencies from 0.1 to $100 \mathrm{rad} \mathrm{s}^{-1}$ using a fresh sample. The steady shear viscosities of the paste were measured with shear rates from 1 to $100 \mathrm{~s}^{-1}$.

2.7 Water Loss, Moisture Content, and Water Activity, Geometrical Properties, Colors, Texture Analysis, and Sensory Evaluation of the Cookies

Measurements of the water loss, moisture content, water activity, geometrical properties, colors, texture analysis, and sensory evaluation of the cookies were followed the method described by Inglett et al. (2016).

\subsection{Statistical Analysis}

All data from replicated samples were analyzed with analysis of variance using Duncan's multiple comparison to determine significant differences $(P<0.05)$ between treatments (SAS Institute, 1999).

\section{Results and Discussion}

\subsection{Water Holding Capacity (WHC) and Water Soluble Index (WSI)}

Figure 1 showed all measured samples WHC. The WHC of navy bean flour was $269.9 \mathrm{~g} / 100 \mathrm{~g}$ that was the highest, while amaranth flour's WHC was $107.5 \mathrm{~g} / 100 \mathrm{~g}$ that was the lowest (Figure. 1). The WHC increased as the amounts of navy bean flour in amaranth-navy bean blends increased. The reasonable explanation for this is that navy beans contain high amount of dietary fiber and proteins. Qiu et al. reported that fiber structures and networks and fiber hydrophilic properties may result in high WHC (Qiu, et al., 2017). Furthermore, the greater amount of proteins of navy beans is also responsible for high WHC (22.33 g/100 g) (Zayas, 1997). Comparing to wheat flour alone, the amaranth-navy bean composites had higher WHC (Figure 1). The high WHC along with their nutrients made amaranth-navy bean composites be good candidates in different applications in the food industry.

Water solubility index (WSI) of amaranth flour had the highest WSI among all measured samples (Figure 1). The WSI increased as the amount of amaranth in composite increased (Figure 1). The WSI for amaranth-navy bean 3:1 composite was greater than that for wheat flour alone. The WSI for amaranth-navy bean 1:1 composite was similar to that for wheat flour alone. The great WSI of amaranth-navy bean composites can lead to greater digestibility. The above WSI results implied that the amaranth-navy bean 3:1 and 1:1 composites could replace 
wheat flour in the food products with same or better WSI. There are many factors that can affect the values of WSI including material's composition, formulation, and pre-processing treatments, etc. (Oikonomou \& Krokida, 2012). It has been reported that when starch depolymerization increased and the length of amylose and amylopectin chains shortened, the WSI increased (Balandran-Quintana et al., 1998). Similarly, Hernandez-Diaz and coworkers observed that the lower WSI was related with lower starch degradation (Hernandez-Diaz et al., 2007). Another report showed that gelatinizing higher WSI products would need less energy (Kaur \& Singh, 2006).
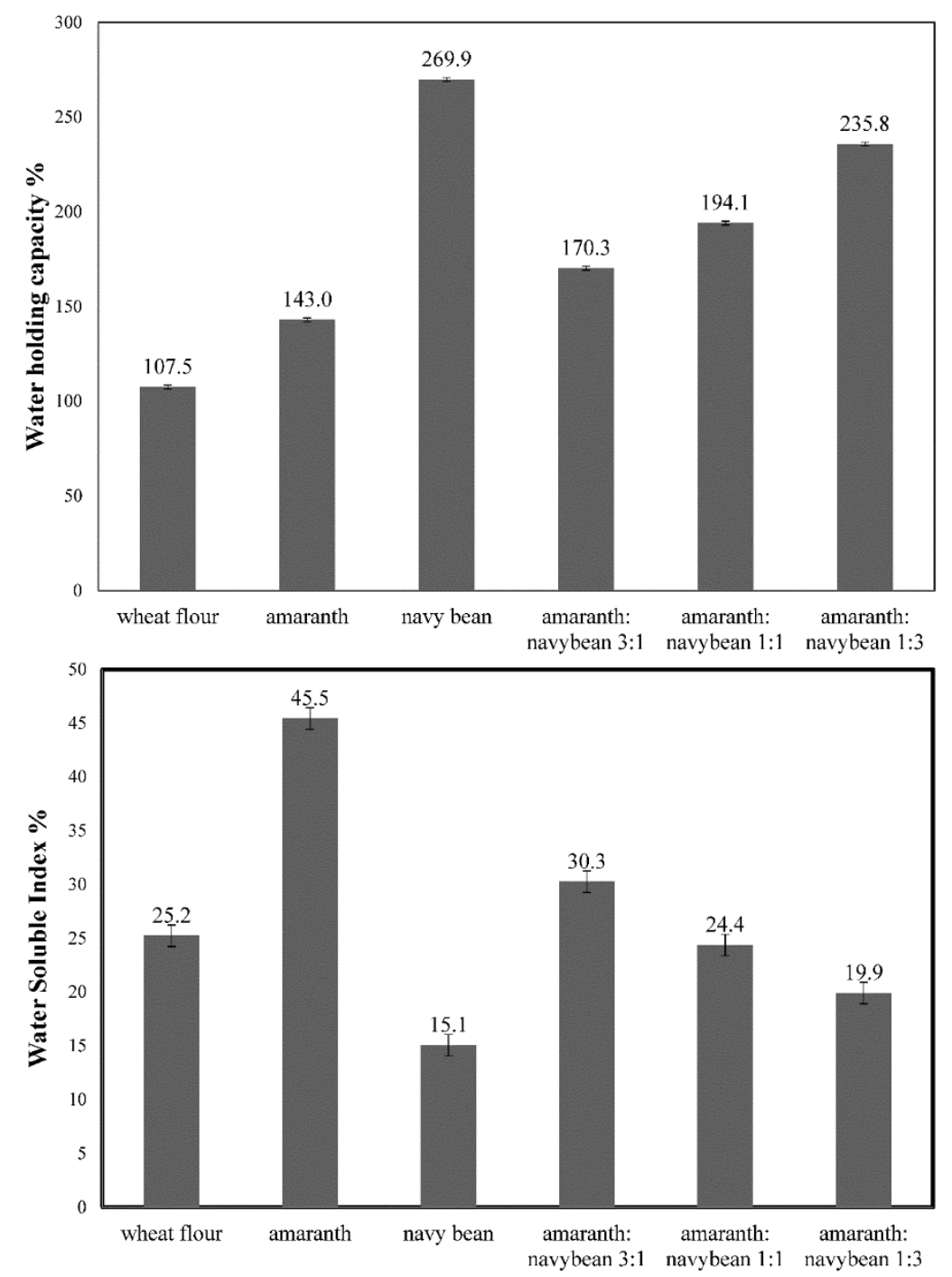

Figure 1. Water holding capacities and water soluble index of amaranth, navy bean, amaranth-navy bean composites, and wheat flour

\subsection{RVA Pasting Properties}

The pasting viscosity curves during the heating and cooling for all studied materials are displayed in Figure 2 . The viscosity of the amaranth flour sample increased sharply $(\sim 58 \mathrm{cP} / \mathrm{min})$ during heating, and displayed the highest initial viscosity peak $(640 \mathrm{cP})$ at $95^{\circ} \mathrm{C}$ and final viscosity $(\sim 678 \mathrm{cP})$ at $50^{\circ} \mathrm{C}$. The viscosities for wheat flour showed an initial peak $(\sim 250 \mathrm{cP})$ that was lower than those for amaranth and amaranth-navy bean $3: 1$, and sharply reduced after the initial peak. Both wheat flour and amaranth flour contained high carbohydrate contents. During heating, starch granule swelling and gelatinization made its viscosity increasing, and decreasing after the gelatinization (Guha et al., 1998). When heating pregelatinized flour, these characteristics were observed (Lai \& Cheng, 2004). The viscosities for navy bean flour had little change during the heating, and had the smallest setback viscosity $(\sim 100 \mathrm{cP})$ among all measured materials. From Figure 2, we can see that amaranth-navy bean 
composites possessed higher values with the amount of amaranth flour in the blends increased. Apparently, the great amaranth viscosities mainly contributed the high viscosities of the amaranth-navy bean composites. The great values of the amaranth-navy bean composites' viscosities should also come from the interactions between contents of amaranth flour and navy bean flour.

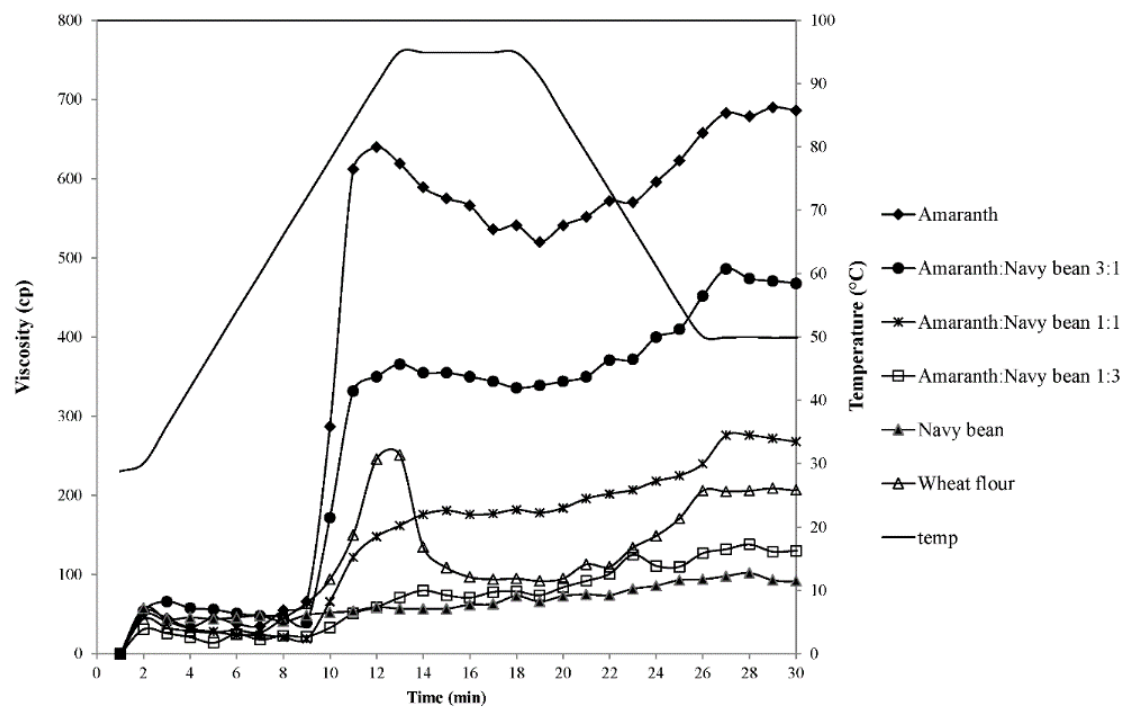

Figure 2. Pasting viscosities of amaranth, navy bean, amaranth-navy bean composites, and wheat flour suspensions

\subsection{Rheological Properties of Composites Suspensions}

The linear dynamic rheological properties elastic (storage) moduli G' and viscous (loss) moduli G" vs. frequency for all measured samples are displayed in Figure $3 \mathrm{a}$. The $\tan (\delta)$ values can also partially reveal the material behaviors (Figure $3 b$ ). Loss tangent, $\tan (\delta)=\mathrm{G}^{\prime \prime} / \mathrm{G}^{\prime}$, is a dimensionless value that compares the amount of energy lost during a test cycle to the amount of energy stored during this time. The loss tangent indicates whether more viscous-like $(\tan (\delta)>1)$ or more elastic-like $(\tan (\delta)<1)$ properties predominate in a sample. The $\tan (\delta)$ has been used for food products to indicate the strong relationship between viscous behavior and the degree of hydrolysis such as casein (Gravier et al., 2004). For all studied materials, the elastic moduli G' were greater than viscous moduli G" within the measured frequency range. These results indicated that all of the studied samples showed viscoelastic-solid behaviors (Gravier et al., 2004). Wheat flour suspension exhibited the greatest viscoelastic behavior among all studied materials, while the navy bean flour suspension showed the weakest property (Figure $3 a)$. The G' and G" for navy bean flour suspension and amaranth-navy bean 1:3 composite suspension exhibited stronger frequency dependence and higher $\tan (\delta)$ values (Figure $3 a \& 3 b$ ) than the other samples. These results indicated that navy bean flour and amaranth-navy bean 1:3 composite suspensions possessed more fluid-like behavior than the others. The moduli for wheat flour, amaranth flour, amaranth-navy bean 1:1 composite, and amaranth-navy bean 3:1 composite suspensions exhibited slight frequency dependence; and $\mathrm{G}^{\prime}$ were higher than $\mathrm{G}^{\prime \prime}$ and the loss tangent less than one over the measured frequency range (Figure 3a \& $3 \mathrm{~b}$ ) suggesting viscoelastic solid properties (Ferry, 1980). The dynamic rheological properties for the amaranth-navy bean 3:1 composite suspensions were very close to those for amaranth flour suspensions, which suggested that amaranth contributed majorly the amaranth-navy bean composite viscoelastic behavior. In addition, the properties of all measured amaranth-navy bean composites suspensions were similar to those of wheat flour suspension even with some lower moduli and higher $\tan (\delta)$ values (Figure $3 b$ ). These results implied that the amaranth-navy bean composites could be a good candidate to replace wheat flour as a gluten-free material, and the food products made from the amaranth-navy bean composites would be a little softer or similar to those made from wheat flour; or even might not be detected by chewing.

Rheological properties of raw food materials can be used to identify and predict their behaviors during food processing. The viscosities of the samples versus shear rate are illustrated in Figure 3c. The shear rate range of 1 to $100 / \mathrm{sec}$ was used due to most food processing and mastication operation in this range. Shear thinning behaviors were observed over the entire measured shear rates at $25^{\circ} \mathrm{C}$ for all studied samples (Figure 3c). Many 
food materials exhibit shear thinning behaviors such as rice, soy, and wheat flour. Because during shearing, the polymers chains and coils are broken and disrupted (Salamone, 1996). Wheat flour suspensions had the highest viscosity, followed by amaranth flour, composites, and navy bean flour suspensions (Figure 3c). The viscosities of all measured amaranth-navy bean composites suspensions were lower than those of wheat flour suspensions (Figure 3c), which suggests that the processing energy to produce food products from the amaranth-navy bean composites should be lower to produce food products from the wheat flour. Many kinds of materials are dealt with in food processing. Most of them possess shear thinning behavior that will have several potential advantages because the viscosities will be reduced with increasing shear rates. Shear thinning behavior for a material would consume less energy during the process comparing to the shearing thickening behavior. Szczesniak and Farkas found that polysaccharide solutions could be easily and quickly swallowed at higher shear rates (Szczesniak \& Farkas, 1962). Therefore, shear thinning behavior of a material can not only benefit the processing energy consumption, but can also contribute a light and non-slimy mouth feeling.
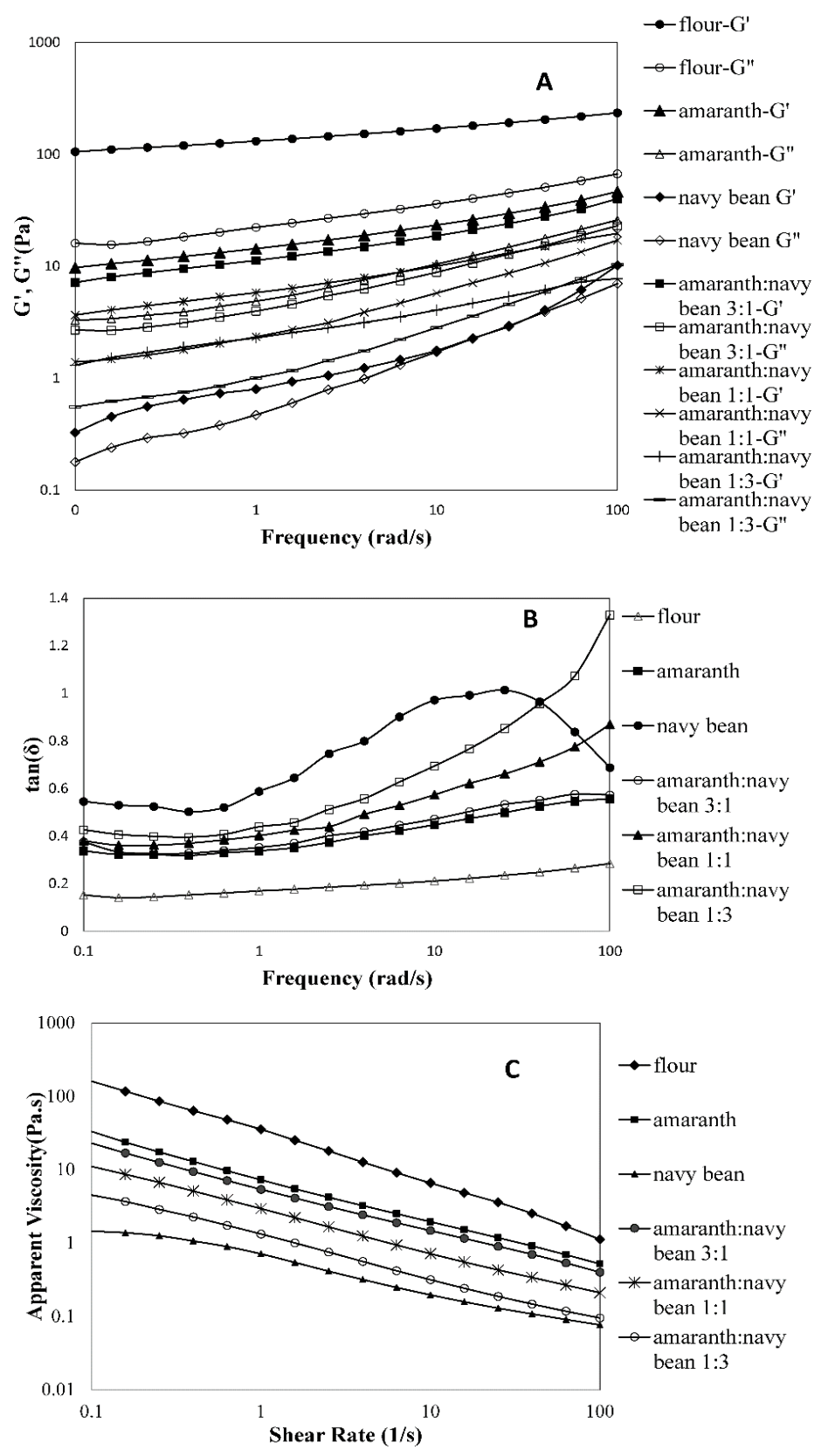

Figure 3. Rheological properties of amaranth, navy bean, amaranth-navy bean composites, and wheat flour suspensions. A: Dynamic viscoelastic properties; B: Values of $\tan (\delta)$ versus frequencies $(\mathrm{rad} / \mathrm{s}) ; \mathrm{C}$ : Apparent viscosity versus shear rate 


\subsection{Geometrical Properties of Cookies}

Cookie qualities were determined by width, thickness, and cookie spread factor. The largest diameter $(6.96 \mathrm{~cm})$ was observed for wheat flour cookies and the smallest diameter $(6.28 \mathrm{~cm})$ for cookies made by navy bean flour (Table 1). It was evident that the width was affected by amaranth, navy bean flour and their composites. The results showed that the width of the cookies using amaranth flour and navy bean flour was $4.9 \%$ and $9.8 \%$ smaller than wheat flour cookie, respectively. Similar to cookies with navy bean flour, the widths of cookie made of amaranth-navy composites were about 8-9\% smaller than cookies using wheat flour. The small diameter value of cookies may be attributed to high protein and fiber content as well as high WHC that could make dough less spreadable compared to the dough with wheat flour. In contrast to cookie width, cookies containing amaranth $(1.33 \mathrm{~cm})$ and amaranth-navy bean $3: 1$ composite $(1.33 \mathrm{~cm})$ were thickest whereas cookies containing wheat flour were thinnest (1.14) among all cookies. The thickness of the cookies using amaranth, amaranth-navy composites, and navy bean flour were all significantly thicker than the cookies with wheat flour. In addition, the thickness increased slightly as the amount of amaranth increased. This is probably due to high protein and mineral content, such as $\mathrm{Ca}, \mathrm{P}, \mathrm{Fe}, \mathrm{P}$, expanding the thickness after absorbing water and baking. The differences were also found in the spread factor as expected. Wheat flour cookies had the highest spread ratio (6.11) followed by cookies containing navy bean flour (5.09) and amaranth flour (4.96). The spread factor increased from 4.75 to 4.90 as amount of navy bean increased in composites, but the increase were not statistically significant. The results showed that diameter, thickness, and spread factor were all influenced by the use of amaranth, navy bean, and their composites compared to cookies with wheat flour. However, the cookies using amaranth had the highest volume due to the highest thickness while the volume of wheat flour cookie was the lowest as a result of the lowest thickness. Overall, all cookies using amaranth, navy bean and their composites had higher volume, in another words, higher yield than wheat flour cookies.

Table 1. The geometrical properties of cookies

\begin{tabular}{|c|c|c|c|c|c|c|}
\hline \multirow{2}{*}{ Products } & \multicolumn{2}{|c|}{ Width $(\mathrm{cm})$} & \multicolumn{2}{|c|}{ Thickness (cm) } & \multirow{2}{*}{$\begin{array}{l}\text { Volume } \\
\mathrm{cm}^{3}\end{array}$} & \multirow{2}{*}{$\begin{array}{l}\text { Spread factor } \\
\text { width/thickness }\end{array}$} \\
\hline & before & after & Before & after & & \\
\hline Wheat flour & 6 & $6.96 \pm 0.04^{\mathrm{a}}$ & 0.7 & $1.14 \pm 0.01^{\mathrm{d}}$ & $12.44^{\mathrm{d}}$ & $6.11 \pm 0.07^{\mathrm{a}}$ \\
\hline Amaranth & 6 & $6.62 \pm 0.03^{\mathrm{b}}$ & 0.7 & $1.33 \pm 0.00^{\mathrm{a}}$ & $13.85^{\mathrm{a}}$ & $4.96 \pm 0.02^{\mathrm{bc}}$ \\
\hline Navy bean & 6 & $6.28 \pm 0.04^{\mathrm{d}}$ & 0.7 & $1.23 \pm 0.02^{\mathrm{c}}$ & $12.15^{\mathrm{e}}$ & $5.09 \pm 0.06^{\mathrm{b}}$ \\
\hline Amaranth: navy bean $3: 1$ & 6 & $6.33 \pm 0.03^{\text {cd }}$ & 0.7 & $1.33 \pm 0.00^{\mathrm{a}}$ & $13.26^{\mathrm{b}}$ & $4.75 \pm 0.02^{\mathrm{d}}$ \\
\hline Amaranth: navy bean $1: 1$ & 6 & $6.39 \pm 0.06^{c}$ & 0.7 & $1.32 \pm 0.02^{\mathrm{a}}$ & $13.27^{\mathrm{b}}$ & $4.84 \pm 0.09^{\text {cd }}$ \\
\hline Amaranth: navy bean $1: 3$ & 6 & $6.32 \pm 0.09^{c}$ & 0.7 & $1.29 \pm 0.01^{\mathrm{b}}$ & $12.78^{\mathrm{c}}$ & $4.90 \pm 0.10^{\mathrm{c}}$ \\
\hline
\end{tabular}

Means \pm standard deviation; $\mathrm{n}=3$; means followed by the same letter within the same column are not significantly different $(P>0.05)$.

\subsection{Texture of Dough and Cookies}

The texture analysis of dough and cookies made of all studied samples are presented in Table 2 . The navy bean flour cookie dough had the highest penetrating force of $7.85 \mathrm{~N}$, followed by amaranth-navy bean 1:3 cookie dough of $4.96 \mathrm{~N}$, while the wheat flour cookie dough had the lowest value of penetrating force $(1.71 \mathrm{~N})$. The amaranth flour, navy bean flour and their composites doughs were harder than wheat flour dough. All composites doughs had higher values of penetrating force than amaranth dough but lower than navy bean dough. The cookie dough hardness was influenced by the navy bean flour level in the dough - the more navy bean flours, the harder of the doughs. This trend of dough hardness was similar to above water holding capacities testing implying that dough hardness may be related to WHC. On the other hand, the cookies made of navy bean flour required the least cutting force $(15.49 \mathrm{~N})$ to break the cookies whereas dough with amaranth needed the maximum cutting force $(76.73 \mathrm{~N})$ followed by wheat flour dough. The composites cookies required less cutting force than wheat flour cookies. Apparently, the cookies made with harder doughs would exhibit more brittle behavior after baking. 
Table 2. The textural properties of doughs and cookies

\begin{tabular}{lll}
\hline Products & $\begin{array}{l}\text { Dough hardness } \\
\text { Penetrating force }(\mathrm{N})\end{array}$ & $\begin{array}{l}\text { Cookie hardness } \\
\text { Cutting force }(\mathrm{N})\end{array}$ \\
\hline Wheat flour & $1.71 \pm 0.04^{\mathrm{f}}$ & $52.39 \pm 2.6^{\mathrm{b}}$ \\
Amaranth & $3.47 \pm 0.00^{\mathrm{e}}$ & $76.73 \pm 0.02^{\mathrm{a}}$ \\
Navy bean & $7.85 \pm 0.01^{\mathrm{a}}$ & $15.49 \pm 0.03^{\mathrm{f}}$ \\
Amaranth: navy bean $3: 1$ & $4.23 \pm 0.18^{\mathrm{d}}$ & $28.86 \pm 0.71^{\mathrm{c}}$ \\
Amaranth: navy bean $1: 1$ & $4.73 \pm 0.20^{\mathrm{c}}$ & $24.59 \pm 0.72^{\mathrm{d}}$ \\
Amaranth: navy bean 1:3 & $5.96 \pm 0.17^{\mathrm{b}}$ & $19.86 \pm 0.29^{\mathrm{e}}$ \\
\hline
\end{tabular}

Means \pm standard deviation; $\mathrm{n}=3$; means followed by the same letter within the same column are not significantly different $(P>0.05)$.

\subsection{Water Loss, Moisture Content, and Water Activity of Cookies}

Water losses during the cookie baking were from $9.18 \%$ to $10.95 \%$ (Table 3). The cookie with wheat flour lost the most water (10.95) whereas amaranth flour cookie lost the least water $(9.18 \%)$. The cookie with wheat flour had the lowest moisture contents (5.35\%) among all cookies. The remaining cookies had similar moisture content ranging from 6.00 to $6.42 \%$, which were all significantly higher than cookies made by wheat flour. That is the evidence that amaranth and navy bean can preserve cookies moisture after baking due to their high fiber and protein contents. Cookie's water activity is very important to predict its stability and safety regarding microbial growth and lipid oxidation rates. Water activities of all measured cookies were in the ranged of 0.389 to 0.451 (Table 3). For the reference, the water activities for spoilage by bacteria, yeasts and molds, are 0.90 , $0.85-0.88$, and 0.80 , respectively (Smith, 2007).

Table 3 . The water loss, moisture content, and water activity of cookies

\begin{tabular}{llll}
\hline Products & Water loss during baking $\%$ & Cookie moisture $\%$ & Water activity aw \\
\hline wheat flour & $10.95 \pm 0.22 \mathrm{a}$ & $5.35 \pm 0.00 \mathrm{~d}$ & $0.389 \pm 0.00 \mathrm{c}$ \\
Amaranth flour & $9.18 \pm 0.15 \mathrm{~b}$ & $6.05 \pm 0.00 \mathrm{bc}$ & $0.447 \pm 0.006 \mathrm{a}$ \\
Navy bean flour & $10.48 \pm 0.48 \mathrm{ab}$ & $6.42 \pm 0.08 \mathrm{a}$ & $0.428 \pm 0.02 \mathrm{~b}$ \\
Amaranth - Navy bean $3: 1$ & $9.20 \pm 1.24 \mathrm{~b}$ & $6.31 \pm 0.08 \mathrm{a}$ & $0.448 \pm 0.004 \mathrm{a}$ \\
Amaranth - Navy bean 1:1 & $9,69 \pm 0.63 \mathrm{ab}$ & $6.00 \pm 0.05 \mathrm{c}$ & $0.451 \pm 0.009 \mathrm{a}$ \\
Amaranth - Navy bean 1:3 & $9.42 \pm 0.04 \mathrm{ab}$ & $6.13 \pm 0.01 \mathrm{~b}$ & $0.420 \pm 0.013 \mathrm{~b}$ \\
\hline
\end{tabular}

Means \pm standard deviation; $\mathrm{n}=3$; means followed by the same letter within the same column are not significantly different $(P>0.05)$.

\subsection{Color of Cookies}

The navy bean flour cookies were darkest in color $\left(L^{*}: 59.53\right)$ among all cookies because the 100 value of dimension $L^{*}$ means lightness for white and 0 value for black (Table 4). The positive and negative value $a^{*}$ indicates redness and greenness for the cookies respectively. All the cookies showed different extent of the redness. Wheat flour cookies had the $15.58 a^{*}$ value, which was the highest among all measured cookies showing the strongest redness. Since the positive value of $b^{*}$ demonstrates the yellowness extent of the cookies, all studied cookies revealed some levels of yellowness (Table 4).

Table 4. The color of cookies

\begin{tabular}{llll}
\hline Products & $\mathrm{L}^{*}$ & $\mathrm{a}^{*}$ & $\mathrm{~b}^{*}$ \\
\hline Wheat flour & $60.52 \pm 1.88 \mathrm{c}$ & $13.29 \pm 0.97 \mathrm{~b}$ & $35.17 \pm 0.46 \mathrm{~b}$ \\
Amaranth flour & $63.95 \pm 1.09 \mathrm{ab}$ & $11.31 \pm 0.72 \mathrm{c}$ & $30.68 \pm 0.22 \mathrm{e}$ \\
Navy bean flour & $59.53 \pm 0.99 \mathrm{c}$ & $15.58 \pm 0.78 \mathrm{a}$ & $36.66 \pm 0.31 \mathrm{a}$ \\
Amaranth - Navy bean $3: 1$ & $62.77 \pm 0.79 \mathrm{~b}$ & $11.59 \pm 0.52 \mathrm{c}$ & $30.45 \pm 0.24 \mathrm{e}$ \\
Amaranth - Navy bean $1: 1$ & $65.18 \pm 1.32 \mathrm{a}$ & $11.18 \pm 0.81 \mathrm{c}$ & $31.89 \pm 0.49 \mathrm{~d}$ \\
Amaranth - Navy bean 1:3 & $63.46 \pm 1.55 \mathrm{ab}$ & $12.83 \pm 0.62 \mathrm{~b}$ & $33.43 \pm 0.71 \mathrm{c}$ \\
\hline
\end{tabular}

Means \pm standard deviation; $\mathrm{n}=3$; means followed by the same letter within the same column are not significantly different $(P>0.05)$. 


\subsection{Sensory Evaluation}

Table 5 showed the sensory analysis data for all studied cookies. The color, texture, flavor, and overall scores for all cookies were in the ranged of 6.7 to $8.3,6.5$ to $8.5,6.1$ to 8.1 , and 6.3 to 8.4 , respectively (Table 5 ). Wheat flour cookies had all highest scores compared with the other measured cookies indicating wheat flour cookies had the best tasting. However, the other studied cookies were also acceptable and likable. The evaluation scores for amaranth flour cookies were the closest to those for wheat flour cookies (Table 5). All scores for composites cookies were similar to each other (Table 5).

The additional flavors of cocoa powder, vanilla, cinnamon, and almond extracts were used in cookies with amaranth-navy bean 1:1 composite for improving flavors. The flavor scores for amaranth-navy bean 1:1 composite cookies with vanilla, cinnamon, and almond extracts were 7.93, 7.60, 7.67, respectively, which were close to that of wheat flour cookies (8.10). The flavor was significantly improved by vanilla extract, cinnamon, and almond extracts except cocoa powder (Table 5). Chocolate cookies using cocoa powder usually require more sugar and fat. We used the AACC method that is for sugar cookie with low sugar content. The flavor of cookies with cocoa would be expected to be better, if the chocolate cookies with cocoa powder used more sugar and fat. The texture score of cookies with vanilla flavor was better compared to cookies without flavor, which is probably due to the judgment on texture that was influenced by the likeness to vanilla.

Table 5. Sensory evaluation for cookies using wheat, amaranth, navy bean flour and their composites

\begin{tabular}{lllll}
\hline Products & Color & Texture & Flavor & Overall \\
\hline Wheat flour (plain) & $8.30 \pm 0.67 \mathrm{a}$ & $8.40 \pm 0.74 \mathrm{a}$ & $8.10 \pm 0.74 \mathrm{a}$ & $8.40 \pm 0.52 \mathrm{a}$ \\
Amaranth flour (plain) & $7.10 \pm 1.20 \mathrm{bc}$ & $7.40 \pm 0.52 \mathrm{bc}$ & $7.10 \pm 0.99 \mathrm{bcd}$ & $7.20 \pm 0.92 \mathrm{bcd}$ \\
Navy bean flour (plain) & $6.70 \pm 1.64 \mathrm{c}$ & $6.80 \pm 1.03 \mathrm{~cd}$ & $6.60 \pm 1.07 \mathrm{de}$ & $6.55 \pm 1.20 \mathrm{de}$ \\
Amaranth - Navy bean 3:1 (plain) & $6.70 \pm 1.34 \mathrm{c}$ & $6.50 \pm 1.78 \mathrm{~d}$ & $6.10 \pm 1.37 \mathrm{e}$ & $6.30 \pm 1.25 \mathrm{e}$ \\
Amaranth - Navy bean 1:3 (plain) & $7.10 \pm 1.37 \mathrm{bc}$ & $7.20 \pm 0.42 \mathrm{bcd}$ & $7.20 \pm 1.40 \mathrm{bcd}$ & $7.25 \pm 1.23 \mathrm{bcd}$ \\
Amaranth - Navy bean 1:1 (plain) & $7.40 \pm 1.43 \mathrm{abc}$ & $7.10 \pm 0.74 \mathrm{bcd}$ & $6.69 \pm 1.03 \mathrm{cde}$ & $7.10 \pm 0.99 \mathrm{bcde}$ \\
Amaranth - Navy bean 1:1(cocoa) & $6.93 \pm 0.80 \mathrm{bc}$ & $6.93 \pm 0.88 \mathrm{~cd}$ & $6.80 \pm 1.00 \mathrm{cde}$ & $6.87 \pm 0.92 \mathrm{cde}$ \\
Amaranth - Navy bean 1:1(vanilla) & $7.67 \pm 0.82 \mathrm{abc}$ & $7.80 \pm 0.88 \mathrm{ab}$ & $7.93 \pm 0.88 \mathrm{ab}$ & $7.87 \pm 0.83 \mathrm{ab}$ \\
Amaranth - Navy bean 1:1 (cinnamon) & $7.47 \pm 0.52 \mathrm{abc}$ & $7.53 \pm 0.83 \mathrm{bc}$ & $7.60 \pm 0.83 \mathrm{abc}$ & $7.53 \pm 0.83 \mathrm{bc}$ \\
Amaranth - Navy bean 1:1 (almond) & $7.80 \pm 0.68 \mathrm{ab}$ & $7.27 \pm 0.72 \mathrm{bcd}$ & $7.67 \pm 0.72 \mathrm{abc}$ & $7.67 \pm 0.82 \mathrm{abc}$ \\
\hline
\end{tabular}

Means \pm standard deviation; means followed by the same letter within the same column are not significantly different. The number 1 referred to dislike extremely; 2 to dislike very much; 3 to dislike moderately; 4 to dislike slightly; 5 to neither like nor dislike; 6 to like slightly; 7 to like moderately; 8 to like very much; and 9 to like extremely.

\section{Conclusion}

The gluten-free amaranth-navy bean composites improved nutritional value, water holding capacity, and the pasting properties. The rheological and geometrical properties, the texture, and the color were affected by amaranth flour and navy bean flour. Overall, amaranth-navy bean composites are suitable for making cookies, which sensory scores were acceptable. The flavorings with vanilla, cinnamon, and almond extracts improved sensory scores that were to close the cookies with wheat flour and higher than the cookies using the same formula without flavoring. This work suggested that the amaranth-navy composites should be good potential candidates as gluten-free materials to replace wheat flour in some food products.

\section{Conflict of interest}

The authors declare no conflict of interest.

\section{References}

AACC International. (2000). Approved Methods of the American Association of Cereal Chemists (10 ${ }^{\text {th }}$ ed.) Methods I0-50D and 10-52. AACC International, St. Paul, MN, U.S.A.

Ade-Omowaye, B. I. O., Taiwo, K. A., Eshtiaghi, N. M., Angersbach, A., \& Knorr, D. (2003). Comparative Evaluation of the Effects of Pulsed Electric Field and Freezing on Cell Membrane Permeabilisation and Mass Transfer during Dehydration of Red Bell Peppers. Innovative Food Science \& Emerging Technologies, 4, 177-188. https://doi.org/10.1016/S1466-8564(03)00020-1

Alegbejo, Jo. (2013). Nutritional Value and Utilization of Amaranthus (Amaranthus spp.) - A Review Bayero. Journal of Pure and Applied Sciences, 6, 1. https://doi.org/10.4314/bajopas.v6i1.27 
Ayo, J. A. (2001). The effect of amaranth grain flour on the quality of bread. International Journal of Food Properties, 4, 341-351. https://doi.org/10.1081/JFP-100105198

Balandran-Quintana, R. R., Barbosa-Canovas, G. V., Zazueta-Morales, J. J., Anzaldua- Morales, A., \& Quintero-Ramos, A. (1998). Functional and nutritional properties of extruded whole pinto bean meal (Phaseolus vulgaris L.). Journal of Food Science, 63, 113-116. https://doi.org/10.1111/j.1365-2621.1998.tb15688.x

CGIAR. (2017). Improving Nutrition and Health. Retrieved June 16, 2017 from http://grainlegumes.cgiar.org/why-grain-legumes-matter/improving-nutrition-and-health/.

Czerwiński, J., Bartnikowska, E., \& Leontowicz, H. (2004). Oat (Avena sativa L.) and amaranth (Amaranthus hypochondriacus) meals positively affect plasma lipid profile in rats fed cholesterol-containing diets". Journal of Nutritional Biochemistry, 15, 622-629. http://dx.doi.org /10.1016/j.jnutbio.2004.06.002

de la Barca, A. M. C., Rojas-Martínez, M. E., Islas-Rubio, A. R., \& Cabrera-Chávez, F. (2010). Gluten-free breads and cookies of raw and popped amaranth flours with attractive. Plant Foods for Human Nutrition, 65, 241-246. https://doi.org/10.1007/s11130-010-0187-z

Ferry, J. D. (1980). Viscoelastic properties of polymers (3rd ed.). New York: John Wiley.

Gallagher, E., Gormley, T. R., \& Arendt, E. K. (2004). Recent advances in the formulation of gluten-free cereal-based products. Trends in Food Science \& Technology, 15, 143-152.

https://doi.org/10.1016/j.tifs.2003.09.012

Gravier, N. G., Zaritzky, N. E., \& Califano, A. N. (2004). Viscoelastic behavior of refrigerated and frozen low-moisture Mozzarella cheese. Journal of Food Science, 9, 123-128. https://doi.org/10.1111/j.1365-2621.2004.tb13364.x

Guha, M., Zakiuddin Ali, S., \& Bhattacharya, S. (1998). Effect of barrel temperature and screw speed on rapid viscoanalyser pasting behaviour of rice extrudate. International Journal of Food Science and Technology, 3, 259-266. https://doi.org/10.1046/j.1365-2621.1998.00189.x

Ha, V., Sievenpiper, J. L., de Souza, R. J., Jayalath, V. H., Mirrahimi, A., Agarwal, A., ... Jenkins, D. J. (2014). Effect of dietary pulse intake on established therapeutic lipid targets for cardiovascular risk reduction: A systematic review and meta-analysis of randomized controlled trials. Canadian Medical Association Journal, 186, E252-262. https://doi.org/10.3945/ajen.115.124677.

Health Line Newsletter. (2017). Folate deficiency. Retrieved April 04, 2017 from http://www.healthline.com/health/folate-deficiency\#overview1.

Hernandez-Diaz, J. R., Quintero-Ramos, A., Barnard, J., \& Balandran-Quintana, R. R. (2007) Functional properties of extrudates prepared with blends of wheat flour/pinto bean meal with added wheat bran. Food Science and Technology International, 13, 301-308. https://doi.org/10.1177/1082013207082463

Hoseney, R. C., \& Rogers, D. E. (1994). Mechanism of sugar functionality in cookies:the science of cookie and cracker production (Ist edn). In: Faridi H (ed) American Association of Cereal Chemists, St. Paul, MN, 203-225.

Inglett, G. E, Chen, D., \& Liu, X. S. (2014). Properties of amaranth flour with functional oat products. Journal of Food Research, 3, 6. https://doi.org/10.5539/jfr.v3n6p1

Inglett, . E., Chen D., \& Liu X. S. (2016). Physical properties of gluten free sugar cookies containing teff and functional oat products. Journal of Food Research, 5, 3. https://doi.org/10.5539/jfr.v5n3p72

Kaur, M., \& Singh, N. (2006). Relationships between selected properties of seeds, flours, and starches from different chickpea cultivars. International Journal of Food Properties, 9, 597-608. https://doi.org/10.1080/10942910600853774

Lai, H. M., \& Cheng, H-H. (2004). Properties of pregelatinized rice flour made by hot air or gum puffing. International Journal of Food Science and Technology, 39, 201-212.

Macvean, D., \& Pöll, E. (1997). Chapter 8: Ethnobotany. In Tropical Tree Seed Manual, USDA Forest Service, edt. ozzo J. A.

Martirosyan, D. M., Miroshnichenko, L. A., Kulakova, S. N., Pogojeva, A. V., \& Zoloedov, V. I. (2007) Amaranth oil application for coronary heart disease and hypertension. Lipids Health Disease, 6, 1. https://dx.doi.org/10.1186\%2F1476-511X-6-1 
McPherson, R. (1992). Dietary fiber - a perspective. In Spiller, G. A. (ed.) Dietary Fiber in Human Nutrition. CRC Handbook, 2nd Edition. Boca Raton, Florida: CRC Press. Pp. 7-11.

Myers, L. R., \& Putnam, H. D. (1988). Growing Grain Amaranth as a Specialty Crop. In Crop Systems. University of Minnesota. FS-03458-GO.

Oikonomou, N. A., \& Krokida, M. K. (2012). Water absorption index and water solubility index prediction for extruded food products. International Journal of Food Properties, 15, 157-168. https://doi.org/10.1080/10942911003754718

Qiu, S., Yadav, M. P., \& Yin, L. (2017). Characterization and functionalities study of hemicellulose and cellulose components isolated from sorghum bran, bagasse and biomass. Food Chemistry, 230, 225-233. https://doi.org/10.1016/j.foodchem.2017.03.028

Salamone, J. C. (1996). Polymeric Materials Encyclopedia. CRC Press, Boca Raton, FL., USA.

SAS Institute INC. (1999). The $S A S^{\circledR}$ system for Windows ${ }^{\circledR}$, version 8e. Cary, NC.

Smith P. G. (2007). Applications of Fluidization to Food Processing, Introduction. Wiley-Blackwell. (pp. 116-117).

Szczesniak, A. S., \& Farkas, E. (1962). Objective characterization of the mouthfeel of gum solutions. Journal of Food Science, 27, 381-385. https://doi.org/10.1111/j.1365-2621.1962.tb00112.x

University of Maryland Medical Center. (2017). Vitamin K. Retrieved April 04, 2017 from http://umm.edu/health/medical/altmed/supplement/vitamin-k\#ixzz33t70aIeT. Accessed 04/05/2017.

USDA. (2017). National Nutrient Database for Standard Reference. Retrieved April 04, 2017 from http://ndb.nal.usda.gov/ndb/search/list.

Zayas, J. F. (1997) Water Holding Capacity of Proteins. In the book 'Functionality of Proteins in Food' by J. F. Zayas. Publisher: Springer-Verlag Berlin Heidelberg. Chapter 2 (pp. 76-133)

\section{Copyrights:}

Copyright for this article is retained by the author(s), with first publication rights granted to the journal.

This is an open-access article distributed under the terms and conditions of the Creative Commons Attribution license (heep://creativecommons.org/licenses/by3.0). 